\title{
What is the Importance of Psychological Measures to Determine Readiness to Return to Sports After Anterior Cruciate Ligament Reconstruction?
}

\section{Tate Newmarch}

University of Toronto Orthopaedic Sports Medicine Program (UTOSM), Women's College Hospital

\section{Marcel Betsch}

University Hospital Mannheim

Roman Michalik ( $\nabla$ rmichalik@ukaachen.de)

RWTH Aachen University Hospital

\section{Tim Dwyer}

University of Toronto Orthopaedic Sports Medicine Program (UTOSM), Women's College Hospital

\section{Daniel Whelan}

University of Toronto Orthopaedic Sports Medicine Program (UTOSM), Women's College Hospital Jaskarndip Chahal

University of Toronto Orthopaedic Sports Medicine Program (UTOSM), Women's College Hospital John Theodoropoulos

University of Toronto Orthopaedic Sports Medicine Program (UTOSM), Women's College Hospital

\section{Research Article}

Keywords: Anterior cruciate ligament reconstruction, Psychological measures, Return to sport, Objective criteria

Posted Date: August 4th, 2021

DOI: https://doi.org/10.21203/rs.3.rs-745201/v1

License: (c) (i) This work is licensed under a Creative Commons Attribution 4.0 International License. Read Full License 


\section{Abstract}

\section{Background:}

Recent studies have suggested that psychological factors are important components of successful return to sports (RTS) after anterior cruciate ligament reconstruction (ACLR). The purpose of this study was to survey physicians on their criteria used to determine readiness to RTS after ACLR and understand the significance of psychological factors on RTS.

\section{Methods:}

A survey was designed to understand the practices of clinicians managing rehabilitation after ACLR consisting of 25 questions divided in 3 different sections, including one section about psychological scores and factors affecting RTS. The survey was delivered to three North-American orthopaedic sports medicine organizations.

\section{Results:}

The total number of respondents was $113.95 \%$ of respondents considered psychological tests at least "somewhat important" (33\% "important", 23\% selected "very important"). Routine use of psychological tests in practice was only reported by $35 \%$ of respondents. The ACL-Return to Sport after Injury Scale was the most frequently used psychological test $(23 \%)$. Fear of reinjury was considered the most common patient-cited psychological factor affecting RTS. Psychological factors ranked 8th out of 9 outcomes measures in determining readiness to RTS.

\section{Conclusion:}

This study demonstrates a discrepancy between the importance of psychological tests and the frequency of use in practice. Additional education on this topic, web-based applications and a multidisciplinary approach may increase the usage of psychological tests to determine RTS after ACLR.

\section{Introduction}

Anterior cruciate ligament (ACL) ruptures are disabling injuries of the knee that compromise mechanical stability and alter joint biomechanics [1]. These changes lead to considerable functional deficiencies and significant time off from sport [12]. The ACL is the most commonly injured ligament in the knee and although an exact number is unknown, it is estimated that a rupture occurs in 1/3500 individuals per year within the United States and around 125 000-200 000 ACL reconstructions (ACLR) are performed annually [8, 9]. Lyman et al. [28] reported steady increases in the rate of ACLR frequency, which may coincide with increases in both recreational and competitive sports participation $[28,30]$.

Over the last few years, there has been a large interest in proposing criteria designed to successfully determine readiness to return to sports (RTS) after ACLR [39]. Recent meta-analyses and systematic 
reviews have reported that the overwhelming majority of physicians use a large variety of different functional and objective measures as their RTS criteria $[9,11,39]$. However, at 1 year following ACLR, approximately only $1 / 3$ of athletes RTS at their preinjury level and all patients after ACLR seemed at an increased risk for a second ACL injury $[6,7]$.

Generally, RTS criteria include subjective and objective criteria as well as test batteries that athletes must satisfy in their final stages of rehabilitation to be cleared for competition [16]. Despite the attention RTS has received there is currently no gold standard in criteria to determine RTS [9, 11,39]; and the validity of many of the tests remains unknown [15]. A prospective study following 158 professional soccer players who were cleared for competition after ACLR found that those who were unable to pass a RTS test battery had a 4x greater likelihood of a secondary ACL injury. However, 12 of 26 who later suffered a second ACL injury did pass the RTS test battery [24]. Furthermore, a recent meta-analysis of 18 studies including a variety of RTS test batteries such as functional measures, strength assessment and clinical examination determined that few athletes successfully pass RTS criteria and that there is little evidence that passing RTS criteria reduces the risk of ACL injuries [39].

Low RTS rates after ACLR may indicate that other factors may be involved in optimal recovery and assessment of an athlete's rehabilitation status. This discrepancy has prompted a growing body of literature demonstrating the importance of psychological factors in successful RTS $[2,5,22,23,25,27$, 36]. The most frequently cited reason for failing to RTS following ACLR is fear of reinjury, a phenomenon not readily observed with current objectively based measures [3,5]. However, there is evidence that psychological readiness and particularly fear of reinjury can be modified, once identified, with appropriate intervention [2]. Despite these positive findings, it is unknown if psychological tests are currently routinely used to determine RTS after ACLR $[9,11]$.

The purpose of this study was to survey the importance of psychological measures used to determine RTS after ACLR. Furthermore, we were interested in the criteria that are used at present by healthcare providers to determine readiness to RTS after ACLR. We hypothesize that most physicians acknowledge the importance of psychological measures to determine RTS after ACLR; however, we believe that only a small proportion actually use them.

\section{Methods}

A team of fellowship trained orthopaedic sports medicine surgeons, all experienced in managing patients with ACLR, collaborated to develop an electronic survey. The initial phase of development consisted of a literature search to identify outcome and psychological measures, as well as objective criteria commonly used by healthcare professionals to determine readiness to RTS after ACLR. All references were reviewed by the development team and a preliminary questionnaire was built guided by previously published reports and clinical expertise. Next, the survey was tested among the development team for format, inclusion of content, clarity and functionality. Finally, we performed pilot testing among a group of orthopaedic surgeons. All suggestions from this pilot testing were considered and modifications to the 
survey were made. The final survey consisted of 25 questions divided in 3 different sections: i) clinician demographics and practice information ii) subjective and objective measures to determine readiness to RTS after ACLR iii) psychological scores and factors affecting RTS.

We published the survey online using SurveyMonkey (SurveyMonkey Inc., San Mateo, CA, USA). The survey was disseminated through SurveyMonkey and through the following professional sports medicine organizations: American Orthopaedic Society of Sports Medicine (AOSSM), Canadian Association of Sports and Exercise Medicine (CASEM), and the Arthroscopy Association of Canada (AAC). The complete survey is available in the Appendix.

\section{STATISTICAL ANALYSIS}

All response data from completed questionnaires was extracted from SurveyMonkey and incorporated into a comprehensive database within Microsoft Excel (Microsoft, Redmond, USA). Raw categorical data was rearranged into a binary cleaned data sheet for simpler manipulation. Response rates for a given answer choice to each question were demonstrated as proportions.

The two final questions were rank-based that required an ordered selection of 7-9 variables based on perceived importance or frequency. The final ranking of each selection was communicated via a summed product. The answer choice with the largest average ranking was the most preferred choice. The weighting system is as follows:

- The \#1 choice has a weight of 5

- The \#2 choice has a weight of 4

- The \#3 choice has a weight of 3

- The \#4 choice has a weight of 2

- The \#5 choice has a weight of 1

This was then used in the following formula to develop a final ranked score for each answer choice:

$\mathrm{w}=$ weight of ranked position

$\mathrm{X}=$ response count for answer choice

$$
\frac{x_{1} w_{1}+x_{2} w_{2}+x_{3} w_{3} \ldots x_{n} w_{n}}{\text { Totalresponsecount }}
$$

\section{Results}

\section{Clinician demographics and practice information}


The total number of respondents from all three organizations was 113 (Table 1), which corresponds to a $4 \%$ response rate. Sixty-four (57\%) survey respondents were orthopaedic surgeons and forty-one (36\%) were primary care sports physicians (Table 2). Seventy-three (65\%) respondents indicated that they have more than 10 years of clinical experience providing care to athletes. There was a large breadth in the type and level of athletes that responding clinicians routinely manage. The most commonly managed sport was soccer $(n=94)$ followed by American Football $(n=90)$, and ice hockey $(n=84)$. Fifty-four clinicians indicated that they provide care to professional athletes, which mainly played in the National Hockey League (NHL) followed by the Major League Soccer (MLS) and the National Football League (NFL) (Table $3)$.

Table 1

Clinician specialty and years of experience

\begin{tabular}{|lll|}
\hline Specialty & Frequency (n) & Percent (\%) \\
\hline Orthopaedic surgeon & 64 & 57 \\
\hline Primary Care Sports Physician & 41 & 36 \\
\hline Other* & 8 & 7 \\
\hline Total & 113 & 100 \\
\hline Experience & Frequency (n) & Percent (\%) \\
\hline $0-5$ years & 25 & 22 \\
\hline $5-10$ years & 15 & 13 \\
\hline$>10$ years & 73 & 65 \\
\hline *5 primary care physicians, 3 physical therapists & \\
\hline
\end{tabular}


Table 2

Sport and caliber of athletes managed by clinicians

\begin{tabular}{|llllll|}
\hline Sport & $\mathbf{n}$ & Level & $\mathbf{n}$ & League & $\mathbf{n}$ \\
\hline Soccer & 94 & Amateur & 97 & NHL & 31 \\
\hline Football & 90 & Recreational & 92 & MLS & 13 \\
\hline Hockey & 84 & College & 88 & NFL & 10 \\
\hline Basketball & 81 & Professional & 54 & MLB & 8 \\
\hline Baseball & 58 & Other & 9 & NBA & 7 \\
\hline Track & 55 & & & Other & 38 \\
\hline Tennis & 49 & & None & 48 \\
\hline Other & 43 & & & \\
\hline * MLB = Major League Baseball; NBA = National Basketball Association \\
\hline
\end{tabular}

\section{Subjective and objective measures}

Time after ACLR (bone-patellar tendon-bone graft) as an objective measure generated a large consensus in that $98 \%$ of clinicians believed no athlete should RTS within 6 months of ACLR, with $42 \%$ indicating 69 months is sufficient time for RTS whereas $54 \%$ considered $9-12$ months necessary. Similar responses occurred for hamstring tendon graft ACLR with $39 \%$ waited for at least 6-9 months vs. $55 \%$ for $9-12$ months ( $2 \%$ 3-6 months and $5 \%>12$ months). High agreement was observed with postoperative pain levels and the use of imaging as indicators for RTS assessment with $98 \%$ of respondents reporting athletes should have a Visual Analogue Scale (VAS) score of $0-3$ and $83 \%$ believing no imaging is required to be cleared for return. Clinical findings that indicate readiness to RTS were a lack of muscle atrophy $(91 \%)$, lack of joint effusion $(90 \%)$ and no signs of swelling $(76 \%)$. The most important clinical test to determine stability of the operated knee was the Lachman test (92\%), followed by the Pivot-Shift Test $(69 \%)$, and meniscal tests (54\%). Most clinicians stated that knee flexion (95\%) of the operated leg should be at least to $100^{\circ}$ and knee extension should be between 0 and $5^{\circ}(90 \%)$ before patients can RTS.

Respondents selected a diverse set of Patient Reported Outcome Measures (PROMs) as tools to determine readiness to RTS (Fig. 1A). The Subjective Knee Evaluation form was the most commonly used PROMs with a $39 \%$ response rate followed by the International Knee Documentation Committee (IKDC) score (25\%). The majority of respondents use the Single Leg Hop Test $(81 \%)$ or the Vertical Jump Test as functional tests for their RTS decision (Fig. 1B). All responding clinicians considered lower extremity muscle strength symmetry important measures of ACLR rehabilitation (76\% very important, $22 \%$ important, $2 \%$ somewhat important). More specifically, nearly all respondents stated that symmetrical strength in the quadriceps and hamstrings are necessary for RTS (95\% and 92\% respectively); however only $77 \%$ and $69 \%$ reported that they objectively measure quadriceps and hamstring strength respectively. The most frequently reported methods for measuring lower extremity strength in athletes include knee 
strength estimates from tests such as hop capacity (57\%), manual muscle testing methods (40\%) and isokinetic dynamometer $(29 \%)$.

\section{Psychological scores and factors}

The importance respondents afforded to psychological tests as tools to determine readiness to RTS can be seen in Fig. 2. Concerning importance, $95 \%(n=106)$ of healthcare professionals considered psychological tests at least somewhat important, with $23 \%(n=26)$ deeming them very important.

Regarding the use of these tests, only $35 \%$ of respondents reported that they routinely use them as part of their practice to decide whether athletes are ready to RTS after ACLR. For those using psychological tests, the particular types can be seen in Fig. 3. The most commonly administered psychological questionnaire was the ACL-Return to Sport after Injury Scale (ACL-RSI) at 23\% followed by the Tampa Scale for Kinesophobia (TSK) (7\%). Respondents were also asked to rank the most frequent patient-cited psychological factors affecting return to play, which can be observed in Table 3. Fear of reinjury was the most common concern with a weighted score of 6.37 and $55 \%$ ranking it number 1 out of 7 options. Lack of confidence in knee was ranked as the second most cited factor with a weighted score of 6.06 with 35\% respondents placing it first. When psychological tests were included with all other outcome measures used to determine readiness to RTS it was ranked 8 out of 9, imaging was the only indices that was placed below, as represented in Table 4. Traditional outcome measures such as functional tests and muscle strength were still considered to be the most important factors when considering RTS (Table 4).

Table 3

Clinician reported patient-cited psychological factors affecting RTS

\begin{tabular}{|lll|}
\hline Rank & Psychological Factor & Weighted Score \\
\hline 1 & Fear of Reinjury & 6.37 \\
\hline 2 & Lack of Confidence in knee & 6.06 \\
\hline 4 & Shift in Priorities & 3.56 \\
\hline 5 & Lack of interest/motivation & 3.50 \\
\hline 6 & Psychosocial & 3.11 \\
\hline 7 & Depression & 3.00 \\
\hline
\end{tabular}


Table 4

Level of importance attributed to outcome measures for RTS

\begin{tabular}{|lll|}
\hline Rank & Outcome Measure & Weighted Score \\
\hline 1 & Functional tests & 7.11 \\
2 & Timing & 6.58 \\
3 & Muscle Strength & 6.58 \\
\hline 4 & Clinical signs & 5.76 \\
\hline 5 & Clinical tests & 5.53 \\
6 & Pain levels & 4.95 \\
7 & Clinical scores & 3.89 \\
\hline 8 & Psychological tests & 3.28 \\
\hline 9 & Imaging & 1.82 \\
\hline
\end{tabular}

\section{Discussion}

The most important finding of this study is that a large proportion of physicians who manage RTS after ACLR believe that psychological issues are important, but few routinely or objectively attempt to measure or treat these issues. This is despite the fact that a large number of patients fail to return to sport after ACLR despite seemingly good functional outcomes - recent evidence has demonstrated that the discrepancy may be in part due to psychological factors [6, 7]. Emotional disturbance, motivation, selfesteem, locus of control, and self-efficacy are strongly associated with an athlete's adherence to rehabilitation programs and readiness to RTS [13]. Because of this association, validated psychological tests are available that can identify athletes at risk of maladaptive psychological responses; albeit a minority of clinicians engage in this practice $[5,41]$. Because low scores on psychological tests strongly suggest poor prognosis, early identification may indicate the need for referral to qualified practitioners as new evidence suggests timely intervention may improve outcomes $[25,36]$.

Our findings on the lack of implementation of psychological tests in practice are consistent with a metaanalysis and systematic review by Ardern et al. [6] which highlighted the lack of biopsychosocial approaches to managing and assessing athletes' readiness to RTS [6]. Since then, a growing body of literature has both provided evidence for the efficacy of psychological measures as necessary components of RTS criteria and made recommendations to include them in the management of ACLR patients $[2,3,5,16,27,36]$. However, these measures are still infrequently used as observed in a review of 209 studies and as confirmed by our results. Their findings revealed that only $12 \%$ of studies used psychologically based measures [11]. In our study only 35\% reported use of psychological tests and ranking 8 out of 9 for RTS outcome measures, indicating that the majority of surgeons still focus on 
objective/functional based RTS measures. At this point it is not known why, in light of the growing evidence, more clinicians are not using psychological scores. One possible factor preventing the inclusion of psychological measures into practice could be physician and clinic time constraints, which may be exacerbated with the introduction of additional questionnaires. Mobile based follow up has been successfully implemented in some orthopaedic populations; both patients and surgeons considered postoperative monitoring via smartphone software in ACLR to be a practicable and an acceptable form of follow up [33]. Furthermore, a mobile patient-based application administered by Higgins et al. [19] was found to accurately assess recovery enough to have avoided follow up for a number of patients [19]. It could be that incorporation of technology into regular patient assessment could enable regular evaluation of patients' psychological readiness for RTS.

The results of our study revealed that the most commonly used psychological test was the ACL-RSI (23\%, Fig. 3); a questionnaire that is strongly associated with RTS [5, 31]. The ACL-RSI has been well validated and used globally with numerous translations; furthermore, a recent short version of the questionnaire was developed and was observed to be robust in predicting RTS outcomes [10, 21, 35, 40,41]. One of the main factors that the ACL-RSI evaluates is fear of reinjury, the most common reason for reduction of cessation of sport after ACLR according to Ardern et al. [4] This is consistent with what clinicians felt was the most common patient-cited reason affecting RTS in our study [4]. Langford et al. [25] tracked fear of reinjury responses throughout the rehab process to assess progress in parallel with functional measures and found that not only did those whom returned to sport at 12 months score more favourably on the ACL-RSI, but that differences between both groups were seen as early as 6 months [25]. Moreover, there is evidence that positive psychological responses including favourable fear of reinjury assessed through the ACL-RSI before and shortly after ACLR were predictive of successful RTS at 12 months following surgery [10].

More importantly, psychological indicators of knee function are readily modifiable risk factors $[3,5,43]$; suggesting that those with lower scores could be provided with increased surveillance and counseling to monitor for maladaptive responses and provided early intervention to change or deter these responses. Additionally, pre-operative psychological factors may influence ACLR outcomes as depressive symptomology has been associated with poor self-reported functional scores both before surgery and 1 year following ACLR [17]. Psychological interventions administered for athletes recovering from ACLR include positive self-talk, guided imagery, relaxation and goal setting [43]. Scherzer et al. [32] demonstrated increased adherence to rehabilitation through goal setting, which yielded a positive relationship with ACLR injury outcome [32]. Furthermore, there is evidence that guided imagery and relaxation sessions for ACLR patients significantly reduces reinjury anxiety [14]. However, most orthopedic surgeons are not trained in psychological interventions, but they may be able to identify athletes who could benefit from these practices, which could prompt collaboration with sport psychologists.

The findings of our study regarding currently used objective measures for determining readiness to RTS are relatively consistent with a 2019 review of 209 studies by Burgi et al. [11] in which, timing, muscle 
strength, clinical examination and functional tests were reported as the most frequent measures to determine RTS after ACLR [11]. In our study, respondents ranked functional tests as the most important outcome measure for RTS (Table 4); above timing, muscle strength and clinical signs and clinical tests. The single leg hop test is the most commonly reported functional assessment tool in both the literature and our survey for determining readiness to RTS $[11,26,42]$. Time required before RTS was considered the 2 nd most important variable; with $98 \%$ of the respondents indicating that a minimum of 6 months is required before RTS. Similar findings were presented by Burgi et al. [11] in 2019, where time was a RTS criterion in 178 of 209 studies with the majority reporting $>6$ months recovery time [11]. However, some argue that unrestricted activity should be delayed further after ACLR as optimal joint function occurs long after the 6-12-month timeline, while others postulate that time as an objective measure is less important than repeated evaluation and follow up to monitor individual progress [29, 34]. Muscle strength ranked 3 out 9 (Table 4) with the overwhelming majority measuring both quadriceps and hamstring muscle strength with the goal to achieve $>85 \%$ strength of the contra-lateral limb. However, there is still debate as to which level of symmetry leads to clinically meaningful differences as well as the methods used to assess strength $[20,38,44]$.

A limitation of our study was the low response rate of $4 \%$. Therefore, it is difficult to generalize our findings to the entire practicing population of those who manage ACLR patients. Our low numbers may serve as a bias. Furthermore, there are limitations inherent to survey research that may be relevant to our study. Respondent bias may be skewed towards those with a vested interest or background in psychological factors involved in ACLR. Additionally, despite anonymity, survey methodology is susceptible to social desirability bias, questions such as the importance of psychological tests in management - with increasing evidence to support their effectiveness - may be overestimated. We were not able to identify differences between different sports, levels of athletes or type of reconstructive surgery as our survey as not designed to determine such differences; however, it would be of interest to investigate this in future studies.

\section{Conclusion}

Psychological factors seem to be important to determine RTS after ACLR based on previous studies. Our results showed that most clinicians are aware of the importance of psychological tests; however, based on our survey only a few currently use them in practice. To address this discrepancy, we suggest further education of physicians on this topic and multidisciplinary treatment plans for patients with ACL injuries and low psychological scores.

\section{Abbreviations}

1. Anterior cruciate ligament (ACL)

2. Anterior cruciate ligament reconstruction (ACLR)

3. Return to sport (RTS) 
4. American Orthopaedic Society of Sports Medicine (AOSSM)

5. Canadian Association of Sports and Exercise Medicine (CASEM)

6. Arthroscopy Association of Canada (AAC)

7. National Hockey League (NHL)

8. Major League Soccer (MLS)

9. National Football League (NFL)

10. Major League Baseball (MLB)

11. National Basketball Association (NBA)

12. Visual Analogue Scale (VAS)

13. Patient Reported Outcome Measures (PROMs)

14. International Knee Documentation Committee (IKDC)

15. ACL-Return to Sport after Injury Scale (ACL-RSI)

16. Tampa Scale for Kinesophobia (TSK)

\section{Declarations}

\section{Ethics approval and consent to participate:}

This initiative was formally reviewed by institutional authorities at Women's College Hospital. The ethics committee ruled that no formal ethics approval is required (2019-0156-E). There was compliance with the principles of the seventh revision of the Declaration of Helsinki, as well as the Good Clinical Practice Guidelines throughout the study. All patients gave their oral and written consent to participate in this study.

\section{Consent for publication:}

Not Applicable.

\section{Availability of data and materials:}

All data generated or analyzed during this study are included in this published article and its supplementary information files.

\section{Competing interests:}

The authors declare that they have no conflicts of interest. 


\section{Funding:}

There was no funding for this study.

\section{Authors' contributions:}

All authors have made substantial contributions to conception and design as well as to analysis and interpretation of data. Furthermore, all authors were involved in drafting or revising the manuscript critically for important intellectual content. All authors have given final approval of the version to be published. Tate Newmarch and Marcel Betsch contributed equally to this manuscript.

\section{Acknowledgements:}

Not Applicable.

\section{References}

1. Andriacchi TP, Birac D. Functional testing in the anterior cruciate ligament-deficient knee. Clin Orthop Relat Res. 1993;(288):40-7.

2. Ardern CL, Taylor NF, Feller JA, Whitehead TS, Webster KE. Sports participation 2 years after anterior cruciate ligament reconstruction in athletes who had not returned to sport at 1 year. Am J Sports Med. 2015;43(4):848-56.

3. Ardern CL, Osterberg A, Tagesson S, Gauffin H, Kvist J. The impact of psychological readiness to return to sport and recreational activities after anterior cruciate ligament reconstruction. Br J Sports Med. 2014;48:1613-9.

4. Ardern CL, Taylor NF, Feller JA, Webster KE. Fifty-five per cent return to competitive sport following anterior cruciate ligament reconstruction surgery: an updated systematic review and meta-analysis including aspects of physical functioning and contextual factors. Br J Sports Med. 2014;48:154352.

5. Ardern CL, Taylor NF, Feller JA, Whitehead TS, Webster KE. Psychological responses matter in returning to preinjury level of sport after anterior cruciate ligament reconstruction surgery. Am J Sports Med. 2013;41(7):1549-58.

6. Ardern CL, Webster KE, Taylor NF, Feller JA. Return to sport following anterior cruciate ligament reconstruction surgery: a systematic review and meta-analysis of the state of play. Br J Sports Med. 2011;45:596-606. 
7. Ardern CL, Webster KE, Taylor NF, Feller JA. Return to the preinjury level of competitive sport after anterior cruciate ligament reconstruction surgery: two-thirds of patients have not returned by 12 months after surgery. Am J Sports Med. 2011;39(3):538-43.

8. Baer GS, Harner CD. Clinical outcomes of allograft versus autograft in anterior cruciate ligament reconstruction. Clin Sports Med. 2007;26(4):661-81.

9. Barber-Westin SD, Noyes FR. Factors used to determine return to unrestricted sports activities after anterior cruciate ligament reconstruction. Arthroscopy. 2011;27(12):1697-705.

10. Bohu Y, Klouche S, Lefevre N, Webster K, Herman S. Translation, cross-cultural adaptation and validation of the French version of the Anterior Cruciate Ligament-Return to Sport after Injury (ACLRSI) scale. Knee Surg Sports Traumatol Arthrosc. 2015;23(4):1192-6.

11. Burgi CR, Peters S, Ardern CL, Magill JR, Gomez CD, Sylvain J, Reiman MP. Which criteria are used to clear patients to return to sport after primary ACL reconstruction? A scoping review. Br J of Sports Med. 2019;53(18):1154-61.

12. Carter ND, Jenkinson TR, Wilson D, Jones DW, Torode AS.Joint position sense and rehabilitation in the anterior cruciate ligament deficient knee. Br J Sports Med. 1997;31(3):209-12.

13. Christino MA, Fantry AJ, Vopat BG. Psychological aspects of recovery following anterior cruciate ligament reconstruction. J Am Acad Orthop Surg. 2015;23(8):501-9.

14. Cupal DD, Brewer BW. Effects of relaxation and guided imagery on knee strength, reinjury anxiety, and pain following anterior cruciate ligament reconstruction. Rehabilitation psychology. 2001;46(1):28-43.

15. Davies G, McCarty E, Provencher M, Manske R. ACL Return to Sport guidelines and criteria. Curr Rev Musculoskelet Med. 2017;10(3):307-14.

16. Dingenen B, Gokeler A. Optimization of the Return-to-Sport paradigm after anterior cruciate ligament reconstruction: A critical step back to move forward. Sports Med. 2017;47(8):1487-500.

17. Garcia GH, Wu H, Park MJ, Tjoumakaris FP, Tucker BS, Kelly JD, Sennett BJ. Depression symptomatology and anterior cruciate ligament injury: incidence and effect on functional outcomea prospective cohort study. Am J Sports Med. 2016;44(3):572-79.

18. Gokeler A, Welling W, Benjaminse A, Lemmink K, Seil R, Zaffagnini S. A critical analysis of limb symmetry indices of hop tests in athletes after anterior cruciate ligament reconstruction: A case control study. Orthop Traumatol Surg Res. 2017;103(6):947-51.

19. Higgins J, Semple J, Murnaghan L, Sharpe S, Theodoropoulos J. Mobile web-based follow-up for postoperative ACL reconstruction: a single-center experience. Orthop J Sports Med. 2017;5(12):2325967117745278. doi: 10.1177/2325967117745278.

20. Ithurburn MP, Altenburger AR, Thomas S, Hewett TE, Paterno MV, Schmitt LC. Young athletes after ACL reconstruction with quadriceps strength asymmetry at the time of Return-to-Sport demonstrate decreased knee function 1 year later. Knee Surg Sports Traumatol Arthrosc. 2018;26(2):426-33.

21. Kvist J, Österberg A, Gauffın H, Tagesson S, Webster K, Ardern C. Translation and measurement properties of the Swedish version of ACL-Return to Sports after Injury questionnaire. Scand J Med 
Sci Sports. 2013;23(5):568-575

22. Kvist J. Rehabilitation following anterior cruciate ligament injury: current recommendations for sports participation. Sports Med. 2004;34(4):269-80.

23. Kvist J, Ek A, Sporrstedt K, Good L. Fear of re-injury: a hindrance for returning to sports after anterior cruciate ligament reconstruction. Knee Surg Sports Traumatol Arthrosc. 2005;13(5):393-97.

24. Kyritsis P, Bahr R, Landreau P, Miladi R, Witvrouw E. Likelihood of ACL graft rupture: not meeting six clinical discharge criteria before return to sport is associated with a four times greater risk of rupture. Br J Sports Med. 2016;50(15):946-51.

25. Langford JL, Webster KE, Feller JA. A prospective longitudinal study to assess psychological changes following anterior cruciate ligament reconstruction surgery. $\mathrm{Br} \mathrm{J}$ Sports Med. 2009;43(5):377-81.

26. Lee DW, Yang SJ, Cho SI, Lee JH, Kim JG. Single-leg vertical jump test as a functional test after anterior cruciate ligament reconstruction. Knee. 2018;25(6):1016-26.

27. Lentz TA, Zeppieri G, George SZ, Tillman SM, Moser MW, Farmer KW, Chmielewski TL. Comparison of physical impairment, functional, and psychosocial measures based on fear of reinjury/lack of confidence and Return-to-Sport status after ACL reconstruction. Am J Sports Med. 2015;43(2):34553 .

28. Lyman S, Koulouvaris P, Sherman S, Do H, Mandl L, Marx R. Epidemiology of anterior cruciate ligament reconstruction: trends, readmissions, and subsequent knee surgery. J Bone Joint Surg. 2009;91(10):2321-8.

29. Nagelli CV, Hewett TE. Should Return to Sport be delayed until 2 years after anterior cruciate ligament reconstruction? Biological and functional considerations. Sports Med. 2017;47(2):221-32.

30. Patel DR, Yamasaki A, Brown K. Epidemiology of sports-related musculoskeletal injuries in young athletes in United States. Transl Pediatr. 2017;6(3):160-6.

31. Sadeqi M, Klouche S, Bohu Y, Herman S, Lefevre N, Gerometta A. Progression of the psychological ACL-RSI score and Return to Sport after anterior cruciate ligament reconstruction: a prospective 2year follow-up study from the French prospective anterior cruciate ligament reconstruction cohort study (FAST). Orthop J Sports Med. 2018;6(12):2325967118812819. doi: $10.1177 / 2325967118812819$

32. Scherzer CB, Brewer BW, Cornelius AE, Van Raalte JL, Petitpas AJ, Sklar JH, Pohlman MH, Krushell RJ, Ditmar TD. Psychological skills and adherence to rehabilitation after reconstruction of the anterior cruciate ligament. J Sport Rehabil. 2001;10(3):165-72.

33. Semple JL, Sharpe S, Murnaghan ML, Theodoropoulos J, Metcalfe KA. Using a mobile app for monitoring post-operative quality of recovery of patients at home: a feasibility study. JMIR mHealth and uHealth. 2015;3(1):e18. doi: 10.2196/mhealth.3929.

34. Shelbourne KD, Klootwyk TE, Decarlo MS. Update on accelerated rehabilitation after anterior cruciate ligament reconstruction. J Orthop Sports Phys Ther. 1992;15(6):303-8. 
35. Slagers AJ, Reininga IHF, van den Akker-Scheek I. The Dutch language anterior cruciate ligament return to sport after injury scale (ACL-RSI) - validity and reliability. J Sports Sci. 2017;35(4):393-401.

36. Sonesson S, Kvist J, Ardern C, Österberg A, Silbernagel KG. Psychological factors are important to return to pre-injury sport activity after anterior cruciate ligament reconstruction: expect and motivate to satisfy. Knee Surg Sports Traumatol Arthrosc. 2017;25(5):1375-84.

37. Thomeé R, Kaplan Y, Kvist J, Myklebust G, Risberg MA, Theisen D, Tsepis E, Werner S, Wondrasch B, Witvrouw E. Muscle strength and hop performance criteria prior to return to sports after ACL reconstruction. Knee Surg Sports Traumatol Arthrosc. 2011;19(11):1798-805.

38. Undheim MB, Cosgrave C, King E, Strike S, Marshall B, Falvey É, Franklyn-Miller A. Isokinetic muscle strength and readiness to return to sport following anterior cruciate ligament reconstruction: is there an association? A systematic review and a protocol recommendation. $\mathrm{Br} \mathrm{J}$ Sports Med. 2015;49(20):1305-10.

39. Webster K, Hewett T. What is the evidence for and validity of Return-to-Sport testing after anterior cruciate ligament reconstruction surgery? A systematic review and meta-analysis. Sports Med. 2019;49(6):917-29.

40. Webster K, Feller J. Development and validation of a short version of the anterior cruciate ligament Return to Sport after Injury (ACL-RSI) Scale. Ortho J Sports Med. 2018;6(4):232596711876376. doi: $10.1177 / 2325967118763763$.

41. Webster KE, Feller JA, Lambros C. Development and preliminary validation of a scale to measure the psychological impact of returning to sport following anterior cruciate ligament reconstruction surgery. Phys Ther Sport. 2008;9(1):9-15

42. Welling W, Benjaminse A, Seil R, Lemmink K, Gokeler A. Altered movement during single leg hop test after ACL reconstruction: implications to incorporate 2-D video movement analysis for hop tests. Knee Surg Sports Traumatol Arthrosc. 2018;26(10):3012-9.

43. Wierike SCM, Sluis A, Akker-Scheek I, Elferink-Gemser MT, Visscher C. Psychosocial factors influencing the recovery of athletes with anterior cruciate ligament injury: A systematic review. Scand J Med Sci Sports. 2013; 23(5):527-40.

44. Zwolski C, Schmitt LC, Thomas S, Hewett TE, Paterno MV. The utility of limb symmetry indices in Return-to-Sport assessment in patients with bilateral anterior cruciate ligament reconstruction. Am J Sports Med. 2016;44(8):2030-8.

\section{Figures}


Fig $1 \mathrm{~A}$

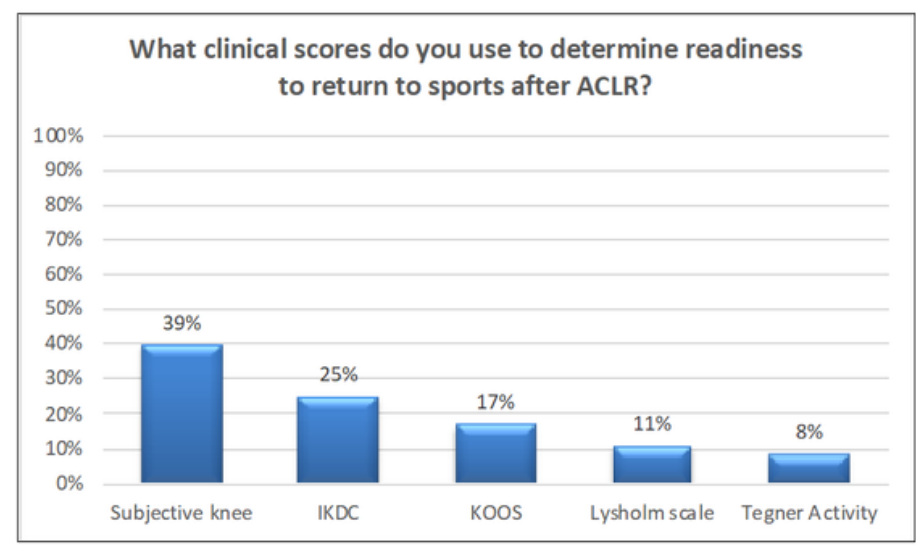

Fig 1B

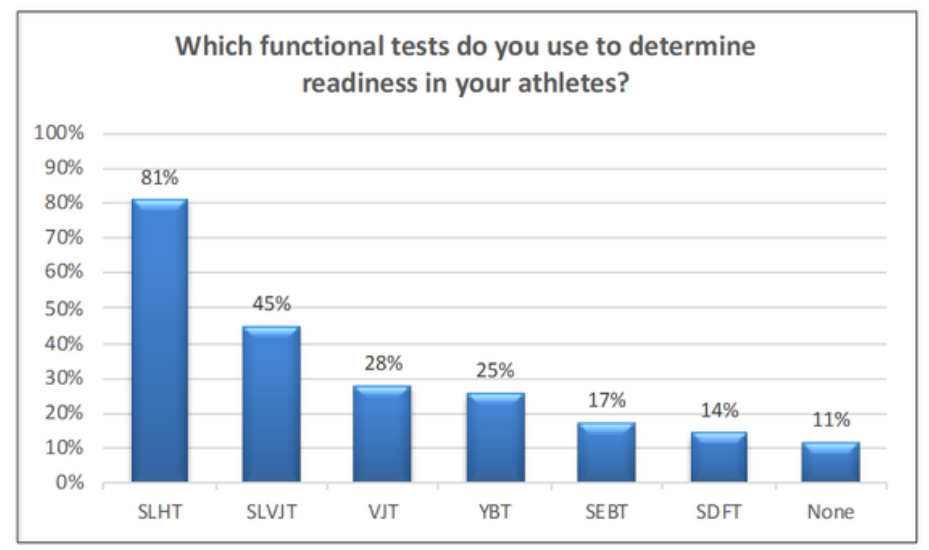

\section{Figure 1}

1A Preferred clinical scores for RTS SKEF: Subjective Knee Evaluation Form; IKDC: International Knee Documentation Committee; KOOS: Knee Injury and Osteoarthritis Outcome Score Fig. 1B Preferred functional tests for RTS SLHT: Single Leg Hop Test; SLVJT: Single Leg Vertical Jump Test; VJT: Vertical Jump Test; Y-Balance Test; SEBT: Star Excursion Balance Test; SDFT: Step Down to Fatigue Test

\section{Fig 2}

\section{How important are psychological tests to determine readiness in athletes?}

\section{$100 \%$}

$90 \%$

$80 \%$

$70 \%$

$60 \%$

$50 \%$

$40 \%$

$30 \%$

$20 \%$

$10 \%$

$0 \%$

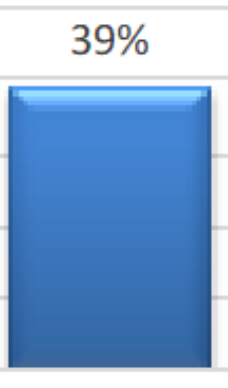

Not important
Somewhat important

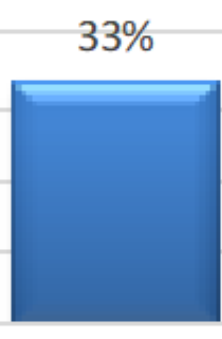

Important

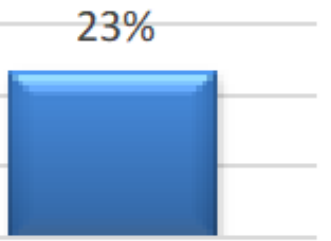

Very Important

\section{Figure 2}




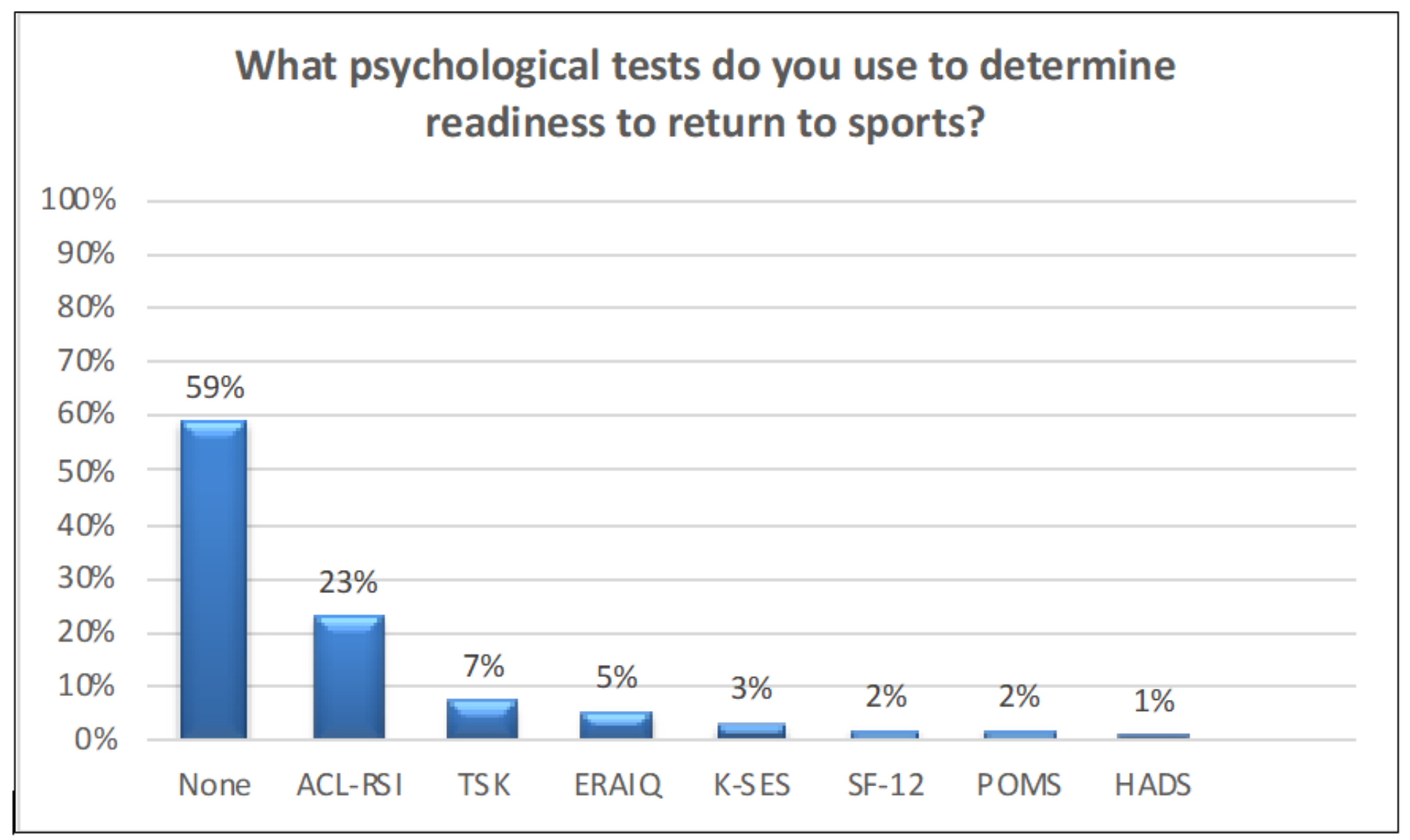

Figure 3

Preferred psychological tests used in practice ACL-RSI: Anterior Cruciate Ligament-Return to Sport after Injury; TSK: Tampa Scale of Kinesophobia; ERAIQ: Emotional Response after Injury Questionnaire; K-SES: Knee-Self Efficacy Score; SF 12: 12-Item Short Form Survey; POMS: Profile of Mood Scale; HADS: Hospital Anxiety and Depression Scale 